\title{
Influence factors of PM2.5 reduction-based on economic data analysis
}

\author{
Yaobo $\mathrm{Shi}^{1}$, Yuquan Wang ${ }^{1}$, and Yun Huang ${ }^{1, *}$ \\ ${ }^{1}$ School of Economics and Management, Xi'an University of Technology, Xi'an, China
}

\begin{abstract}
Starting from China's environmental issues to study the impact of environmental protection fiscal expenditures on PM2.5 concentration reduction. This article uses the panel data of 30 provinces (except Hong Kong, Macao, Taiwan and Tibet) from 2007 to 2017, and uses PM2.5 concentration levels in China's provinces as an explained variable. The results of the panel regression model shows that environmental protection fiscal expenditures have a significant positive effect on PM2.5 reduction environmental policy tools have a significant positive regulatory effect on environmental protection fiscal expenditures and PM2.5 reduction. Increasing environmental protection fiscal expenditures is conducive to promoting PM2.5 reduction.
\end{abstract}

\section{Research background}

China's rapid development has enabled China to become the world's second largest economy in just over forty years. But behind this rapid growth is the sacrifice of the environment. China's high energy consumption and high pollution economic growth method not only caused a lot of waste of resources, but also caused heavy pressure on the environment. Among the 338 prefecture-level and above cities monitored by China in 2018, only $35.8 \%$ of cities had air quality up to the standard, and $64.2 \%$ of cities that did not meet the air quality standard.

The environment has the attributes of public goods, and environmental problems have the nature of externalities, and it is difficult to solve them only by market regulation mechanisms. Since 2007, the Chinese government has set up 211 environmental protection expenditures for environmental protection in fiscal expenditures. The government's fiscal expenditures on environmental protection have increased from 95.582 billion yuan in 2007 to 635.275 billion yuan in 2018 , with an average annual rate. An increase of $15.68 \%$, exceeding the GDP growth rate of $9.70 \%$ over the same period

As an important means for the government to perform environmental governance functions, does environmental protection fiscal expenditures help promote PM2.5 concentration reduction? Does environmental protection fiscal expenditures have a positive impact on PM2.5 concentration reduction? This article will empirically analyze the impact of environmental protection fiscal expenditures on PM2.5 reduction, and draw conclusions that can withstand empirical tests, in order to give full play to the financial role of environmental protection fiscal expenditures.

\section{Research design}

The nature of environmental public goods determines that they cannot be supplied through market mechanisms As a provider of public goods, the state uses fiscal and other economic means to conduct macro-control. Therefore, fiscal expenditure is an important means to protect the environment. There are few studies on the environmental governance effects of environmental protection fiscal expenditures in the existing literature. Among them, more and more scholars have strongly believed that environmental protection fiscal expenditures have a governance effect on environmental pollution. For example, Galinato (2017)1 introduced environment into the endogenous growth model. The empirical results showed that the increase in environmental protection fiscal expenditure can significantly reduce the emission of environmental pollutants and improve the environmental quality. Yu Zhang (2014)2used three panel models to empirically analyze the relationship between environmental protection fiscal expenditures and the three pollutants. The empirical results showed that environmental protection fiscal expenditures have a significant inhibitory effect on the emissions of these three pollutants. Therefore, he proposed Suggestions for increasing fiscal expenditures in areas with serious environmental pollution. Feiran Wang (2015)3 adopted 6 -year provincial panel data from 30 provinces in China and found that the increase in environmental protection fiscal expenditure can significantly reduce the discharge of industrial wastewater, industrial solid waste and industrial sulfur dioxide, that is, increase the amount of environmental protection fiscal expenditure input. It can effectively alleviate pollution. Zhian Yang et al. (2016)4

* Corresponding author: $120376343 @$ qq.com 
used Liaoning Province as the research object to analyze the relationship between environmental protection fiscal expenditures and environmental quality in Liaoning Province. Empirical evidence showed that the increase in environmental protection fiscal expenditures can significantly improve environmental quality. In the environmental governance of environmental protection fiscal expenditures, Shuying Tian et al. (2016)5 believed that environmental protection fiscal expenditures are not only part of fiscal expenditures, but also have policy effects in environmental governance.

To sum up, scholars have explored related issues such as environmental protection fiscal and environmental pollution reduction from different perspectives, and have reached meaningful conclusions. China's provincial panel data (2007-2017) were used in this article to empirically analyze the impact of environmental protection fiscal expenditures on PM2.5 concentration reduction based on econometric models.

\section{Data and methods}

\subsection{Source of data}

The Chinese government began to set up 211 environmental protection expenditures in the fiscal revenue and expenditure in 2007. Therefore, the obtained environmental protection fiscal expenditure data began in 2007. This article uses the provincial panel data of 30 provinces (except Hong Kong, Macao, Taiwan and Tibet) from 2007 to 2017 to establish an economic measurement model of environmental protection fiscal expenditure on PM2.5 concentration reduction.

\subsection{Variable measurement}

\subsubsection{Dependent variable}

This article uses the average annual PM2.5 concentration (PM2.5) of each province as a measure of PM2.5. PM2.5 is not a single pollutant, but a comprehensive environmental pollution index. This article draws on the basis of Jiayuan Xiao et al. (2018)6, used PM2.5 concentration (PM2.5) as explained variables. The reduction of PM2.5 concentration indicates that environmental protection fiscal expenditure has achieved good results.

\subsubsection{The independent variables}

In this article, the environmental protection fiscal expenditure $(\mathrm{Hbzc})$ is represented by the energy conservation and environmental protection fiscal expenditure in the government's fiscal revenue and expenditure. In the treatment of environmental pollution, the nature of the environment as a public product and the negative externalities of environmental problems determine that the government should be the main force for environmental protection, and environmental protection fiscal expenditure is a fiscal expenditure, which is important for environmental pollution control. The investment of environmental protection funds such as investment has a policy-induced effect. Since China only officially increased the expenditure on energy conservation and environmental protection in the fiscal expenditure account in 2007, the establishment time is relatively short. Based on the availability of data and the significance of index selection, the environmental protection fiscal expenditure of local governments is the provincial data of 30 provinces (except Hong Kong, Macao, Taiwan and Tibet) in China after 2007.

\subsubsection{Control variables}

(1) Environmental governance investment (Egi) is represented by the government investment in environmental pollution control. This article uses the total amount of environmental governance investment to measure the status of environmental governance investment. (2) Environmental policy tools (Regulation): In the research on the relationship between environmental policy and environmental protection, the empirical research results of most scholars prove that the intensity of environmental policy is positively correlated with the improvement of environmental quality. This article selects the number of environmental policies and regulations issued by each province in the year as the proxy variable for environmental policy tools. (3) Regional economic level $(G d p)$ : real per capita GDP is used to represent the level of regional economic level. (4) Urbanization rate (City):the urbanization rate is measured by the proportion of the urban population in the current year to the total population living at the end of the year. (5) Industrial Structure (Industry): industrial added value as a proportion of GDP. (6) Trade openness (Open): Total import and export as a measure. The unit of the original trade data is USD, which is converted into RMB using the annual average exchange rate. (7) Investment in fixed assets (Fiv): the total fixed asset investment of the whole society is used to measure the fixed asset investment.

\subsection{Research methods}

The provincial panel data of 30 provinces (except Hong Kong, Macao, Taiwan and Tibet) from 2007 to 2017 were used to establish an economic measurement model of environmental protection fiscal expenditure on PM2.5concentration reduction. In order to avoid the possible deviation of the model estimation caused by the absolute value of different variables, this paper takes logarithm processing for most of the variables in the model.

The model of the impact of environmental protection fiscal expenditure on PM2.5 concentration reduction established in this paper is as follows:

$\ln P M 2.5_{i t}=\alpha_{0}+\alpha_{1} \ln H b z c_{i t}+\alpha_{2} \ln E g i_{i t}+$ $\alpha_{3}$ Regulation $_{i t}+\alpha_{4} \operatorname{lnGdp}_{i t}+\alpha_{5}$ City $_{i t}+$ $\alpha_{6}$ Industry $_{i t}+\alpha_{7}$ lnOpen $_{i t}+\alpha_{8}$ lnFiv $_{i t}+\varepsilon_{i t}$ 


\section{The results and conclusions}

In order to determine the effect model selected by the model, a Hausman statistical test was performed. The test results shows that the random effect model is applicable in each model. Model3 uses the first-order lag term of the explanatory variable as an instrumental variable for further verification. Model 4 further adds the interaction effect of environmental protection fiscal expenditures and environmental policy tools. The test results are shown in the table1:

Table1. regression results of environmental protection fiscal expenditure on PM2.5 reduction

\begin{tabular}{|c|c|c|c|c|}
\hline $\begin{array}{l}\text { MODEL } \\
\text { VARIABLES }\end{array}$ & $\begin{array}{c}(1) \\
\ln P M 2.5\end{array}$ & $\begin{array}{c}(2) \\
\ln P M 2.5\end{array}$ & $\begin{array}{c}(3) \\
I V-\ln P M \\
2.5 \\
\end{array}$ & $\begin{array}{c}(4) \\
\ln P M 2.5\end{array}$ \\
\hline $\ln H b c z$ & $\begin{array}{c}-0.049 * * \\
*\end{array}$ & $\begin{array}{c}-0.072 * * \\
*\end{array}$ & $-0.044 *$ & $-0.055^{* *}$ \\
\hline & $(-4.36)$ & $(-2.85)$ & $(-1.73)$ & $(-2.20)$ \\
\hline $\ln E g i$ & & $\begin{array}{l}0.003 \\
(0.12)\end{array}$ & $\begin{array}{l}0.015 \\
(0.73)\end{array}$ & $\begin{array}{l}0.001 \\
(0.04)\end{array}$ \\
\hline Regulation & & $\begin{array}{l}-0.004 \\
(-0.83)\end{array}$ & $\begin{array}{c}-0.004 * * \\
(-2.09)\end{array}$ & $\begin{array}{l}0.004 \\
(1.16)\end{array}$ \\
\hline $\ln G D P$ & & $\begin{array}{c}0.140^{*} \\
(1.72)\end{array}$ & $\begin{array}{l}0.024 \\
(0.59)\end{array}$ & $\begin{array}{l}0.027 \\
(0.53)\end{array}$ \\
\hline City & & $\begin{array}{l}-0.003 \\
(-1.33)\end{array}$ & $\begin{array}{l}-0.002 \\
(-1.04)\end{array}$ & $\begin{array}{l}-0.003 \\
(-1.42)\end{array}$ \\
\hline Industry & & $\begin{array}{c}-0.007 * * \\
* \\
(-3.55)\end{array}$ & $\begin{array}{c}-0.005^{* *} \\
(-2.52)\end{array}$ & $\begin{array}{c}-0.007 * * \\
* \\
(-3.81)\end{array}$ \\
\hline lnOpen & & $\begin{array}{c}-0.063 * * \\
(-2.35)\end{array}$ & $\begin{array}{c}-0.043 * \\
(-1.72)\end{array}$ & $\begin{array}{l}-0.036 \\
(-1.31)\end{array}$ \\
\hline $\ln F i v$ & & $\begin{array}{l}-0.051 \\
(-1.28)\end{array}$ & $\begin{array}{c}-0.047 * \\
(-1.69)\end{array}$ & $\begin{array}{l}-0.006 \\
(-0.17)\end{array}$ \\
\hline $\begin{array}{l}\text { lnHbcz*Regulati } \\
\text { on }\end{array}$ & & & & $-0.002 *$ \\
\hline Constant & $\begin{array}{c}3.842 * * * \\
(41.17)\end{array}$ & $\begin{array}{c}4.164 * * * \\
(11.61)\end{array}$ & $\begin{array}{c}4.720 * * * \\
(15.40)\end{array}$ & $\begin{array}{c}(-1.66) \\
4.515 * * * \\
(14.49)\end{array}$ \\
\hline Observations & 330 & 330 & 300 & 330 \\
\hline
\end{tabular}

Notes: The values in parentheses denote the standard errors. "***"、“**"and"**"denote significance at the $1 \%$, $5 \%$, and $10 \%$ levels, respectively.

As shown in Table1, we found that: (1) environmental protection fiscal expenditures are significantly negatively correlated with PM2.5 concentration at the level of $1 \%$ both in each model, which shows that environmental protection fiscal expenditures significantly reduce the concentration of PM2.5. Environmental protection fiscal expenditures have a positive and direct effect on reducing PM2.5. (2)The positive correlation between environmental governance investment and PM2.5 concentration is not statistically significant in each model.(3)In model2, the environmental policy tools have no effect on the reduction of PM2.5. When PM2.5 in a first-order lag as instrumental variable putted in Model3, we find that environmental policy tools have a significant negative correlation with PM2.5. It shows that environmental policy tools have a significant lagging effect on PM2.5 reduction. (4) Regional economic level and PM2.5 only have a significant positive correlation in the current period, which indicates that the increase in the level of economic development has led to an increase in the concentration of PM2.5. (5) The negative relationship between urbanization level and PM2.5 is not significant, and may be restricted by the selected indicators, and further research is needed. (6) The industrial structure is significantly negatively correlated with PM2.5 at the level of $1 \%$ in each model, which shows that the optimization of the industrial structure can help reduce the concentration of PM2.5. (7) Trade openness has a significant negative correlation with PM2.5 concentration at the level of 5\% in model 2 and model3. Increased trade openness can significantly reduce PM2.5 concentration, which may be due to the technical effect of trade openness that plays a role in reducing emissions. (8) There is a significant negative correlation between investment in fixed assets and the concentration of PM2.5 in the lagging period. (9)There is a significant negative correlation between the interaction items of environmental protection fiscal expenditures and environmental policy tools and PM2.5 at the level of $10 \%$.

\section{Conclusion}

Based on the above research, we can draw the following conclusions:(1) environmental protection fiscal expenditure has a positive effect on reducing PM2.5 concentration. Increasing environmental protection fiscal expenditures is conducive to promoting PM2.5 reduction (2) The effect of environmental governance investment on PM2.5 reduction needs further study. (3) Environmental policy tools have a significant lagging effect on PM2.5 emission reduction, and strengthening environmental regulations will help reduce PM2.5 concentration. (4) Environmental policy tools not only contribute to the reduction of PM2.5 concentration, but also play a regulatory role in environmental protection fiscal expenditures and PM2.5 concentration, so that environmental protection fiscal expenditures can significantly reduce PM2.5 concentrations. (5) The results of this article prove that the growth of economic development has also exacerbated the problem of environmental pollution.

Fund Project: Shaanxi Provincial Social science Project (2019KRM007); the key research plan of Shaanxi Provincial department of education (18JZ040); Yulin Industry - university - research Project (CXY-2020-083) and Xi ' an university of technology Research Team Project.

\section{Reference}

1. Galinato G I, Islam A, Environment \& Development Economics, 22, 1-24(2017)

2. Yu Zhang, Journal of Qingdao University of Science and Technology, 12,78-81(2014) 
3. Feiran Wang, Research on the environmental governance effects of fiscal and taxation policies, $\mathbf{0 2}$, 38-40(2015)

4. Zhian Yang, Wu Yang, Journal of Shenyang Normal University (Social Science Edition),06,59-62 (2016)

5. Shuying Tian, Dong Wei, Xu Wenli, Exploration of Economic Issues, 07,14-21(2016)

6. Jiayuan Xiao, Pan Liu, Finance and Trade Research,04,68-79(2018) 